\title{
Advances in the molecular regulation of endothelial BMP9 signalling complexes and implications for cardiovascular disease
}

Jennifer H Wood ${ }^{1}$, Jingxu Guo ${ }^{1}$, Nicholas W Morrell ${ }^{1}$ and Wei Li ${ }^{1}$

${ }^{1}$ Department of Medicine, University of Cambridge, Cambridge, United Kingdom

Corresponding Author:

Wei Li

Department of Medicine, University of Cambridge, Level 5, Addenbrooke's Hospital

Box 157, Hills Road, Cambridge, CB2 0QQ

Email:wl225@cam.ac.uk

Tel.: +44 (0) 1223761304

Fax: $+44(0) 1223336846$ 


\section{Abstract:}

Bone morphogenetic protein 9 (BMP9), a member of the transforming growth factor $\beta$ (TGF $\beta$ ) superfamily is a circulating vascular quiescence and endothelial-protective factor, accounting for the majority of BMP activity in plasma. BMP9 and BMP10 bind preferentially to the high affinity type I receptor activin receptor-like kinase 1 (ALK1) on vascular endothelial cells. Recently, a number of reports have highlighted the important roles of BMP9 in cardiovascular disease, particularly pulmonary arterial hypertension (PAH). In vivo, BMP9 activity and specificity are determined by tightly regulated protein-protein recognition with cognate receptors and a co-receptor, and may also be influenced by other proteins present on endothelial cell surface (such as low affinity receptors) and in circulation (such as TGF $\beta$ family ligands competing for the same receptors). In this review, we summarise recent findings on the role and therapeutic potential of BMP9 in cardiovascular disease, and review the current understanding of how the extracellular protein-protein interaction milieu could play a role in regulating endothelial BMP9 signalling specificity and activity. 


\section{Abbreviations:}

BMP: Bone morphogenetic protein; TGF $\beta$ : transforming growth factor $\beta$; ALK1: activin receptorlike kinase 1; PAH: pulmonary arterial hypertension; BMPRII: BMP receptor type II; hPAECs: human pulmonary artery endothelial cells; ENG: endoglin; HHT: hereditary haemorrhagic telangiectasia; AVM: arteriovenous malformation; TAC: transverse aortic constriction; AMD: age-related macular degeneration; ALK1-Fc: ALK1 extracellular domain-Fc fusion protein; GFD: growth factor domain; ActRIIa/b: Activin type II receptor a/b; ActA: activin A; Pro-BMP9: prodomain-bound BMP9; MSCs: mesenchymal stem cells; ECD: extracellular domain; ITC: isothermal titration calorimetry; CV2: crossveinless 2. 


\section{Introduction to bone morphogenetic protein (BMP)9 and endothelial BMP signalling}

BMP9 is synthesised in the liver(1), circulates in blood at active concentrations, and acts as a serum quiescence factor to maintain vascular homeostasis(2). BMP9 acts selectively on vascular endothelial cells, inhibiting endothelial cell apoptosis, migration, proliferation and angiogenesis(2-4). Dysregulated BMP signalling causes endothelial dysfunction which plays a central role in pulmonary arterial hypertension (PAH), a progressive disease with a poor prognosis. Loss-of-function mutations in BMP receptor type II (BMPR2) are the most common genetic cause of PAH(5) and reduced lung vascular expression of BMPRII is a feature of both heritable and idiopathic forms of PAH(6). BMPRII-mediated signalling is pivotal in maintaining endothelial integrity and barrier function. In vitro, loss of BMPRII predisposes human pulmonary artery endothelial cells (hPAECs) to apoptosis, increased proliferation and increases permeability of the hPAEC monolayer. In vivo, loss of BMPRII causes heightened lung vascular permeability(7).

In humans, there are 15 BMP ligands, among which BMP9 shares high sequence similarity only with BMP10 (64\% in the growth factor domain). BMP10, which also signals selectively via the ALK1/BMPRII complex, is exclusively expressed in the right atrium in the adult(8). Bmp9 -/mice are grossly normal apart from defects in lymphatic vessels and delayed closure of the ductus arteriosus(9-12), whereas Bmp10 -/- mice are embryonic lethal(10). Although there have been no reports of differences between BMP9 and BMP10 signalling in endothelial cells in vitro, studies from knockout mice suggest that BMP9 may play a more prominent role in the maintenance of adult vascular homeostasis, whereas BMP10 is indispensable for embryonic development $(2,9-11,13)$. The role of BMP10 in adults is still to be elucidated.

\section{Role and therapeutic potential of BMP9 and BMP10 in cardiovascular disease}


Compromised function in the BMP9 signalling pathway is linked to a number of cardiovascular diseases. Mutations in the BMP9 receptor $A L K 1$ and the co-receptor Endoglin (ENG) are causal for the human autosomal genetic disorder hereditary haemorrhagic telangiectasia (HHT)(14, 15). HHT is characterised by the presence of multiple arteriovenous malformations (AVM), mostly small telangiectasia on the skin or mucous membranes, but larger AVMs may also be found in lungs, liver and brain. Mutations in BMP9 itself were also reported in patients with HHTlike vascular anomaly syndrome(16). The pivotal role of endothelial BMP9 signalling in PAH has been strengthened by recent reports which will be discussed further below. In preclinical studies, the beneficial effects of BMP9 signalling have been demonstrated in several other cardiovascular diseases. For example, in a mouse model of left ventricular heart failure induced by transverse aortic constriction (TAC), Bmp9 knockout mice displayed a more severe fibrotic phenotype, whereas treatment with recombinant BMP9 in wild type mice limited TAC-induced cardiac fibrosis(17). In another report, using adenoviral-mediated gene delivery, BMP9 was shown to prevent oxygen-induced retinal neovascularization in newborn mice and laser injury-induced choroidal neovessel formation in adult mice, suggesting the potential of BMP9 in treating agerelated macular degeneration (AMD)(18).

\section{Role of BMP9 in HHT}

The important roles of BMP9 and BMP10 in HHT have been reviewed recently(19) and are underpinned by the fact that they are the only known high affinity ligands for ALK1 and ENG (20, 21). ALK1 and ENG mutations found in HHT patients have been tested experimentally, with most resulting in compromised protein folding and secretion(22-25). Those ALK1 or ENG mutants that attain cell surface expression exhibit reduced BMP9 signalling $(22,23)$. Further evidence comes from a report that mouse pups receiving neutralising antibodies against BMP9 and 
BMP10 via lactation developed signs of HHT symptoms, including defects in arteriovenous specification and AVMs (26).

\section{Role of BMP9 in PAH}

Genetic evidence strongly supports a pivotal role of compromised endothelial BMP signalling in the development of PAH. Genetic mutations in BMPR2, ALK1 and ENG have all been found in patients with idiopathic or heritable forms of PAH(27-30). Recently, a large-scale whole-genome sequencing study in 1038 PAH index cases not only confirmed the mutations in the BMP9 receptors, but also identified heterozygous pathogenic mutations in BMP9 itself (31). Structural and functional analyses suggested that these mutations lead to reduced cellular secretion of mutant BMP9. Two further studies have confirmed this finding in independent PAH cohorts, with a prevalence of heterozygous $B M P 9$ mutations as high as $6.7 \%$ reported in idiopathic PAH patients from China. In the same report, the authors demonstrated that $B M P 9$ mutation carriers had low plasma levels of BMP9, supporting loss-of-function as the mechanism for PAH in these patients(31-33). There is a single case report of a homozygous recessive nonsense BMP9 mutation in a case of childhood-onset PAH(34). Interestingly, two PAH patients were identified carrying heterozygous mutations in BMP10 in a French cohort(32).

There is also strong non-genetic clinical evidence supporting a causal role for reduced BMP9 signalling in PAH. Patients with cirrhosis are at greatly increased risk of developing PAH and cirrhosis patients with advanced liver disease exhibit very low plasma levels of BMP9. The lowest levels are found in cirrhosis patients who develop PAH (known as portopulmonary hypertension)(35). In fact, low plasma BMP9 levels were a good predictor for the presence of PAH in cirrhosis patients. The same investigators showed inhibition of plasma BMP9 and BMP10 with ALK-Fc exacerbated hypoxia-induced pulmonary hypertension in mice(35). These 
observations are in keeping with our previous observation, that augmentation of endothelial BMP signalling by recombinant BMP9 reverses established PAH in several rodent models(7). In contrast, Tu et al. recently published a study showing that selective BMP9 inhibition partially protects against experimental pulmonary hypertension(36), observations that superficially appear to be at odds with our earlier report(7). Tu et al. proposed that BMP9 confers a vasoconstrictive effect by inducing factors such as endothelin-1 and suppressing vasodilation factors such as adrenomedullin and apelin, whereas our report has shown extensively that exogenous BMP9 exerts anti-apoptotic and anti-proliferative effects on vascular endothelial cells, thereby reversing PAH by correcting endothelial dysfunction(7). Nevertheless, the findings by Tu et al. are of interest and, if confirmed, provide a starting point to examine whether the chronic loss of BMP9 induces vascular changes typical of HHT - with reduced vascular tone and reduced muscularisation of arterioles, as seen in mice that are heterozygous for a targeted deletion in endoglin gene(37). Such changes would protect rodents from pulmonary vasoconstrictive stimuli, but chronic inhibition of BMP9 might be a hazardous approach in PAH patients, given the strong human genetic evidence that loss-of-function in the BMP9 signalling axis promotes the development of PAH(5).

In summary, human genetics studies support a central role of compromised BMP9 signalling in PAH and HHT, and preclinical studies suggest the beneficial effects of recombinant BMP9 in rodent models of $\mathrm{PAH}$, cardiac fibrosis and AMD. Therefore, a thorough understanding of the regulation of the BMP9 signalling complex at molecular level is essential and will greatly facilitate the bench to bedside development of new therapies targeting this pathway.

\section{Current understanding of BMP9 signalling at a molecular level}

Introduction to the components of BMP signalling complexes

BMP9 belongs to the transforming growth factor $\beta$ (TGF $\beta$ ) superfamily, which is comprised of 
over 30 ligands, including BMPs, growth and differentiation factors, activins, and TGF $\beta$ ligands(38). The TGF $\beta$ family is highly conserved in eukaryotes, controlling myriad important processes such as embryonic stem cell self-renewal, differentiation, morphogenesis, and tissue homeostasis. Ligands of the TGF $\beta$ family are generally homodimers, which bind specific transmembrane receptors on the cell surface, inducing the formation of heteromeric complexes consisting two copies of a type I receptor and two copies of a type II receptor. TGF $\beta$ receptors are serine/threonine kinases, initiating signalling via Smad-dependent and Smad-independent signalling pathways to regulate gene expression(39-41). Tight intracellular and extracellular regulation of TGF $\beta$ superfamily signalling helps achieve its myriad biological effects.

There are 15 BMPs in humans, signalling via one of four type I receptors (ALK1, ALK2, ALK3 and ALK6) along with one of three type II receptors (BMPRII, ActRIIa and ActRIIb) (Figure 1A). ALK1 is an endothelial-selective type I receptor, mediating the signalling only from BMP9 and BMP10, whilst BMPRII is a type II receptor for most BMPs. ActRIIa/b can mediate signalling from BMPs as well as from other TGF $\beta$ family ligands, such as activin A (ActA). A high degree of promiscuity has been demonstrated in BMP family ligand-receptor interactions; for example, each ligand can signal through multiple receptor complexes and each receptor pair can mediate the signalling from multiple BMP ligands(42) (Figure 1A). This is largely due to the fact that BMP family ligands and receptors share the same three-dimensional structural fold and signalling complex assembly(40)(and references cited in Table 1). Therefore, different local concentrations of receptors and ligands will have a direct impact on BMP signalling capacity and specificity. BMPs are synthesised as pre-pro-proteins and processed into prodomains and mature growth factor domains (GFDs) upon secretion(43-45). It has been confirmed for BMP9 and BMP10 that the prodomains remain non-covalently bound to the GFDs in the circulation $(4,46)$. Due to the lack of commercially available prodomain bound BMPs, current understanding of extracellular BMP-receptor interactions was largely obtained using only BMP GFDs. In vivo, prodomain- 
bound BMP9 (pro-BMP9) is likely to simultaneously encounter a number of extracellular proteins that might bind itself or its receptors. Figure 1B summarises such extracellular BMP9 protein interaction network. These protein-protein interactions will directly influence BMP9 signalling on endothelial cells.

\section{Structural knowledge of BMP9 signalling}

Molecular mechanisms of BMP signalling have been studied at the structural level for many years. Early efforts were focused on the bone-forming BMPs, such as BMP2 and BMP7, which were investigated clinically as a therapy to promote bone reunion following fracture. Although BMP9 was first reported in 2000(1), it did not attract much attention until 2007 when two groups simultaneously reported that BMP9 is a high affinity ligand for ALK1 and preferentially acts on vascular endothelial cells, inhibiting angiogenesis and conferring vascular homeostasis(3, 20). BMP9 is now one of the best studied BMPs, which alongside BMP2, has the most structural data available (Table 1 and Figure 1C), including three crystal structures for BMP9 GFD alone (1ZKZ, 4MPL and 5I05)(24, 47, 48), two crystal structures of the murine prodomain bound to human GFD (4YCG, 4YCI)(44), one crystal structure for the ternary signalling complex of ALK1:BMP9:ActRIIb (4FA0)(25), and one crystal structure for BMP9 bound to the orphan domain of the co-receptor ENG (5HZW)(24). This has greatly facilitated the understanding of BMP9 regulation and signalling at the molecular level. Equipped with such structural knowledge, we can now begin to pinpoint the specific protein-protein interactions that could potentially regulate the BMP9 signalling, and investigate each interaction experimentally in the correct cellular context.

\section{Type I site binding partners and specificity}


At physiologically relevant concentrations, BMP9 signalling in endothelial cells is exclusively mediated by the high affinity receptor ALK1(3). At higher BMP9 concentrations and after costimulating with lipopolysaccharides or tumour necrosis factor- $\alpha$, ALK2 can also be activated(49, 50). In non-endothelial cells, ALK2 has been shown to mediate BMP9 signalling by siRNA approaches, such as BMP9-mediated osteogenic signalling activity in mesenchymal stem cells (MSCs) and C2C12 myoblasts, but the nature of the interaction between BMP9 and ALK1 or ALK2 in the context of osteogenic activity is not known(51). In addition, BMP9 signalling through ALK2 has also been shown to promote ovarian cancer cell proliferation(52). The direct binding affinities between BMP9 and seven TGF $\beta$ family type I receptors have been measured using extracellular domain-Fc fusion fragments and quantitative ELISA(44). Apart from very high affinity for ALK1-Fc, the binding of BMP9 to three other type I receptors in the TGF $\beta$ family can be detected with three orders of magnitude weaker affinities. Interestingly, although pro-BMP9 showed similar binding affinity for ALK1 to BMP9-GFD, its affinity for ALK2 was too weak to be accurately measured in the same experimental setting(44) (Table 2). It is worth noting that the $\alpha 5$ helix from the prodomain occupies the type I receptor-binding site in the crystal structure(44)(Figure 1C), which may explain why pro-BMP9 has reduced affinity for ALK2. These data suggest that the prodomain may confer some type I site selectivity, although such selectivity in a cell-based activity assay is yet to be shown.

\section{Type II site binding partners and specificity}

The type II site on BMP9 interacts with several partners, including the prodomain, type II receptors and the co-receptor ENG (Figure 1B). Interestingly, these interactions share significant overlap of binding epitopes on BMP9, suggesting they cannot bind BMP9 simultaneously, which has also been confirmed by several Biacore binding studies(21, 44, 53, 54). How the type II receptors displace the prodomain and ENG to form a signalling complex is not known, nor do we 
know whether ENG displacement is required for the formation of the signalling complex. The analysis of the reported affinities (Table 2) for these interactions does not prove that such signalling complex formation is solely dependent on the relative affinities. In addition, although the affinities between ALK1-Fc with both BMP9 GFD and pro-BMP9 are of similar high affinity and mostly consistent between reports regardless of the measurement methods, the binding affinities at the type II sites vary significantly between studies even under similar experimental conditions. Moreover, it is important to point out that receptor extracellular domain (ECD)-Fc fusion proteins were used in all studies; Fc fusion proteins are artificial dimers that may not reflect the true binding affinities by receptors on the cell surface. Lastly, all but one of the studies listed have used solid-surface based binding assays, which do not always reflect binding in solution. The only solution study is the binding of BMP9 to its prodomain using isothermal titration calorimetry (ITC) which gave rise to micromolar affinity(44)(Table 2), two orders of magnitude weaker than the affinities measured for prodomain-GFD interactions of BMP5 and BMP10 using Biacore(45). Therefore, more research is required to investigate how specificity is achieved at the type II site and whether any allosteric interaction or conformational change is required for BMP9 signalling complex formation.

Using signalling assays in PAECs, it has been shown that knocking down BMPR2 alone by siRNA does not lead to a loss of Smad1/5 phosphorylation induced by BMP9 GFD, and simultaneously knocking down both BMPR2 and ACTR2a is required to suppress BMP9-induced Smad1/5 phosphorylation(55). How BMP9 signalling is differentially dependent on BMPRII or ActRIIa remains to be elucidated. In MSCs, it has been shown that expression of ECDs of all three type II BMP receptors, BMPRII, ActRIIa and ActRIIb, can inhibit BMP9-induced osteogenic activity, with ECD of ActRIIb being the most potent. However, MSCs do not express ActRIIb and knockingdown either ACTR2a or BMPR2 in these cells with specific small interfering RNA reduced osteogenic activity of BMP9(56). Because mutations in BMPR2 but not ACTR2a/b are found in 
PAH patients, how BMPRII achieves its unique function in endothelial cells that cannot be replaced by ActRIIa/b is of significant medical importance, and how BMP9 achieves its type II site specificity warrants further investigation.

The other protein that binds to the BMP9 GFD type II site is the prodomain (Figure 1B). Although it has been suggested that the prodomain could bind to its cognate BMP with relatively high affinity(45), we have shown that free prodomain does not inhibit BMP9 or BMP10 signalling in endothelial cells $(4,45,46)$.

\section{Ligand trap and ligand competition}

BMP signalling is also influenced by proteins that function as ligand traps, such as noggin, however, BMP9 and BMP10 are insensitive to noggin inhibition(2,57). It is unclear whether BMP9 and BMP10 are influenced by other endogenous ligand traps. One candidate is crossveinless 2 (CV2), a chordin family BMP ligand trap(58). It was shown that BMP9/ALK1 signalling in endothelial cells can induce the expression of CV2 and that CV2 can bind BMP9 in pull-down and immunoprecipitation assays. In the same report, the authors provide data showing CV2 inhibits BMP9 induced BRE-luciferase activity in bovine aortic endothelial cells(58). A direct binding between BMP9 and CV2 is yet to be shown using purified proteins. In addition to ligand traps, other TGF $\beta$ family members might influence BMP9 signalling in the endothelium. Different TGF $\beta$ family members can bind to the same type II receptors at the same epitope; this leads to a situation whereby the signalling response to a given TGF $\beta$ family cytokine is dependent on the expression, affinity, and accessibility of itself as well as all other TGF $\beta$ family ligands and receptors on specific cells, tissues, and organs. Indeed, Aykul et al. revealed that ActA binds ActRIIa/ActRIIb with high affinity and consequently inhibits BMP9 activity in a human liver carcinoma cell line (HepG2) through receptor competition(59). ActA levels are elevated in clinical and experimental pulmonary hypertension(60). Thus, it is possible that ActA, as well as 
potentially other circulating TGF $\beta$ superfamily ligands, could interfere with BMP9 signalling by competing for the type II receptors on endothelial cells. BMP4 and ActA family ligands have both been found in the circulation $(60,61)$. BMP9 could potentially share BMPRII with BMP4 and ActRIIa/b with ActA family ligands, thus it is essential to establish whether such ligand competition is also present in the context of BMP9 signalling in endothelial cells. Despite BMP9 signalling in HepG2 cells partially inhibited by high concentrations of ActA(59), we found that a 200-fold molar excess of BMP4 or ActA failed to significantly inhibit BMP9 signalling in PAECs. Control experiments showed that ActA is fully active in inducing Smad2/3 phosphorylation in PAECs (Figure 2). The discrepancy between HepG2 and PAECs is probably due to endothelial cells expressing high levels of ALK1 and ENG, which can preferentially capture BMP9 and increase its local concentration at the EC surface. This is another example that the regulation of BMP signalling on target cells is highly context-dependent; we have previously shown that the prodomain of BMP10 can inhibit BMP10 signalling in C2C12 cells but not in PAECs(46). Hence although it is helpful to use model cell lines to dissect receptor and ligand interactions, it is essential to validate the regulation of BMP signalling in the primary, physiologically relevant cell type where cell surface receptor environment also plays a significant role in its signalling capacity and specificity.

\section{Discussion}

This review summarised the current advance of BMP9 in cardiovascular disease and reviewed the known extracellular protein-protein interactions that may impact on BMP9 signalling in the endothelium. Many other factors should be considered when evaluating BMP9 interactions with the endothelium. For example: 1) among the target genes induced by BMP9 in endothelial cells, there are a number of intracellular and extracellular BMP signalling modifiers, such as BMP signalling inhibitors SMAD6, SMURF, ligand trap NOGGIN and BAMBI etc. Such a feedback loop 
seems to be a common theme in TGF $\beta$ family signalling, emphasizing the importance of maintaining BMP signalling at optimum levels. 2) The organism may regulate BMP9 protein stability and mRNA synthesis; for example, we have shown previously that circulating BMP9 protein itself is subject to redox-dependent proteolysis(48). 3) Given that BMP9 and BMP10 share high affinity receptors on the endothelial surface, BMP10 could potentially compensate for BMP9 to a certain degree $(9,10)$. However, the prodomains of BMP9 and BMP10 share less than $30 \%$ identity, which could potentially affect the distribution of pro-BMP9 and pro-BMP10 on vascular endothelium and possibly also endocardium. 4) It was recently reported the presence of BMP9 and BMP10 heterodimer in plasma, which should signal through the same type I receptor ALK1 in endothelial cells as BMP9 therefore could add another layer of complexity to the regulation of BMP9 signalling(62). 5) Many other cellular signalling pathways are known to crosstalk with BMP9 signalling, such as TGF $\beta$, VEGF, Notch, WNT and Hippo signalling pathways(63). The overall physiological outcome of the BMP9 signalling pathway is likely the cumulative effects of different pathways and multiple levels of regulation.

\section{Perspectives}

\section{- The importance of the field}

The circulating BMPs, BMP9 and BMP10, are important players in an emerging axis of vascular endothelial protection. Human genetics studies confirm that loss of signalling via this axis promotes the development of PAH or HHT. Augmentation of circulating BMP9 produced beneficial effects in pre-clinical models of PAH, cardiac fibrosis and AMD, and reversed the loss of functional endothelial BMP9 signalling in rodent models of PAH. A better understanding of the regulation and protein-protein interactions involved in BMP9 signalling complexes will facilitate the therapeutic approaches targeting this pathway in these cardiovascular diseases, 


\section{- Summary of the current thinking}

Human genetic data strongly support a compromised endothelial BMP9/ALK1/BMPRII axis as causative for PAH. In addition, loss-of-function in ENG or ALK1 can cause HHT. Current knowledge from structural biology, protein-protein interactions and signalling assays in human primary endothelial cells have provided a wealth of information on the mechanisms by which BMP9 and BMP10 signal. The specificity and high binding affinity for ALK1 make BMP9 and BMP10 particularly potent ligands on endothelial cells.

\section{- Future directions}

Future research should aim at understanding the paradox why loss-of-function in the BMP9 signalling axis can on the one hand cause HHT and yet also promote PAH. The type II site selectivity of BMP9 and BMP10 requires further elucidation, not only at the protein-protein interaction level, but also in the endothelial cell signalling context; for example, why mutations in BMPRII but not ActRIIa/b cause PAH. Furthermore, a crystal structure containing BMPRII ECD in complex with a BMP ligand is yet to be reported. Understanding how BMP9 interacts with different type II site binding partners to achieve its endothelial protective function at the molecular level will likely provide new insights into the finely balanced signalling events that are important in endothelial protection. 


\section{Acknowledgement:}

This work was supported by the British Heart Foundation grants PG/15/39/31519 and PG/17/1/32532 (both to W.L. and N.W.M.) and CH/09/001/25945 (to N.W.M.). We thank Dr Marko Hyvönen for kindly providing ActA, and Cambridge NIHR Biomedical Research Centre for providing infrastructure support. 


\section{References}

1. Miller AF, Harvey SA, Thies RS, Olson MS. Bone morphogenetic protein-9. An autocrine/paracrine cytokine in the liver. J Biol Chem. 2000;275(24):17937-45.

2. David L, Mallet C, Keramidas M, Lamande N, Gasc JM, Dupuis-Girod S, et al. Bone morphogenetic protein-9 is a circulating vascular quiescence factor. Circ Res. 2008;102(8):914-22.

3. Scharpfenecker M, van Dinther M, Liu Z, van Bezooijen RL, Zhao Q, Pukac L, et al. BMP-9 signals via ALK1 and inhibits bFGF-induced endothelial cell proliferation and VEGF-stimulated angiogenesis. J Cell Sci. 2007;120(Pt 6):964-72.

4. Bidart M, Ricard N, Levet S, Samson M, Mallet C, David L, et al. BMP9 is produced by hepatocytes and circulates mainly in an active mature form complexed to its prodomain. Cell Mol Life Sci. 2012;69(2):313-24.

5. Ormiston ML, Upton PD, Li W, Morrell NW. The promise of recombinant BMP ligands and other approaches targeting BMPR-II in the treatment of pulmonary arterial hypertension. Glob Cardiol Sci Pract. 2015;2015(4):47.

6. Atkinson C, Stewart S, Upton PD, Machado R, Thomson JR, Trembath RC, et al. Primary pulmonary hypertension is associated with reduced pulmonary vascular expression of type II bone morphogenetic protein receptor. Circulation. 2002;105(14):1672-8.

7. Long L, Ormiston ML, Yang X, Southwood M, Graf S, Machado RD, et al. Selective enhancement of endothelial BMPR-II with BMP9 reverses pulmonary arterial hypertension. Nat Med. 2015;21(7):777-85.

8. Neuhaus H, Rosen V, Thies RS. Heart specific expression of mouse BMP-10 a novel member of the TGF-beta superfamily. Mech Dev. 1999;80(2):181-4.

9. Ricard N, Ciais D, Levet S, Subileau M, Mallet C, Zimmers TA, et al. BMP9 and BMP10 are critical for postnatal retinal vascular remodeling. Blood. 2012;119(25):6162-71.

10. Chen H, Brady Ridgway J, Sai T, Lai J, Warming S, Chen H, et al. Context-dependent signaling defines roles of BMP9 and BMP10 in embryonic and postnatal development. Proc Natl Acad Sci U S A. 2013;110(29):11887-92.

11. Levet S, Ciais D, Merdzhanova G, Mallet C, Zimmers TA, Lee SJ, et al. Bone morphogenetic protein 9 (BMP9) controls lymphatic vessel maturation and valve formation. Blood. 2013;122(4):598-607.

12. Levet S, Ouarne M, Ciais D, Coutton C, Subileau M, Mallet C, et al. BMP9 and BMP10 are necessary for proper closure of the ductus arteriosus. Proc Natl Acad Sci U S A. 2015;112(25):E3207-15.

13. Chen H, Shi S, Acosta L, Li W, Lu J, Bao S, et al. BMP10 is essential for maintaining cardiac growth during murine cardiogenesis. Development. 2004;131(9):2219-31.

14. Johnson DW, Berg JN, Baldwin MA, Gallione CJ, Marondel I, Yoon SJ, et al. Mutations in the activin receptor-like kinase 1 gene in hereditary haemorrhagic telangiectasia type 2 . Nat Genet. 1996;13(2):189-95.

15. McAllister KA, Grogg KM, Johnson DW, Gallione CJ, Baldwin MA, Jackson CE, et al. Endoglin, a TGF-beta binding protein of endothelial cells, is the gene for hereditary haemorrhagic telangiectasia type 1. Nat Genet. 1994;8(4):345-51.

16. Wooderchak-Donahue WL, McDonald J, O'Fallon B, Upton PD, Li W, Roman BL, et al. BMP9 mutations cause a vascular-anomaly syndrome with phenotypic overlap with hereditary hemorrhagic telangiectasia. Am J Hum Genet. 2013;93(3):530-7.

17. Morine KJ, Qiao X, York S, Natov PS, Paruchuri V, Zhang Y, et al. Bone Morphogenetic Protein 9 Reduces Cardiac Fibrosis and Improves Cardiac Function in Heart Failure. Circulation. 2018;138(5):513-26. 
18. Ntumba K, Akla N, Oh SP, Eichmann A, Larrivee B. BMP9/ALK1 inhibits neovascularization in mouse models of age-related macular degeneration. Oncotarget. 2016;7(35):55957-69.

19. Tillet E, Bailly S. Emerging roles of BMP9 and BMP10 in hereditary hemorrhagic telangiectasia. Front Genet. 2014;5:456.

20. David L, Mallet C, Mazerbourg S, Feige JJ, Bailly S. Identification of BMP9 and BMP10 as functional activators of the orphan activin receptor-like kinase 1 (ALK1) in endothelial cells. Blood. 2007;109(5):1953-61.

21. Castonguay R, Werner ED, Matthews RG, Presman E, Mulivor AW, Solban N, et al. Soluble endoglin specifically binds bone morphogenetic proteins 9 and 10 via its orphan domain, inhibits blood vessel formation, and suppresses tumor growth. J Biol Chem. 2011;286(34):30034-46.

22. Ricard N, Bidart M, Mallet C, Lesca G, Giraud S, Prudent R, et al. Functional analysis of the BMP9 response of ALK1 mutants from HHT2 patients: a diagnostic tool for novel ACVRL1 mutations. Blood. 2010;116(9):1604-12.

23. Mallet C, Lamribet K, Giraud S, Dupuis-Girod S, Feige JJ, Bailly S, et al. Functional analysis of endoglin mutations from hereditary hemorrhagic telangiectasia type 1 patients reveals different mechanisms for endoglin loss of function. Hum Mol Genet. 2015;24(4):1142-54.

24. Saito T, Bokhove M, Croci R, Zamora-Caballero S, Han L, Letarte M, et al. Structural Basis of the Human Endoglin-BMP9 Interaction: Insights into BMP Signaling and HHT1. Cell Rep. 2017;19(9):1917-28.

25. Townson SA, Martinez-Hackert E, Greppi C, Lowden P, Sako D, Liu J, et al. Specificity and structure of a high affinity activin receptor-like kinase 1 (ALK1) signaling complex. J Biol Chem. 2012;287(33):27313-25.

26. Ruiz S, Zhao H, Chandakkar P, Chatterjee PK, Papoin J, Blanc L, et al. A mouse model of hereditary hemorrhagic telangiectasia generated by transmammary-delivered immunoblocking of BMP9 and BMP10. Sci Rep. 2016;5:37366.

27. International PPHC, Lane KB, Machado RD, Pauciulo MW, Thomson JR, Phillips JA, 3rd, et al. Heterozygous germline mutations in BMPR2, encoding a TGF-beta receptor, cause familial primary pulmonary hypertension. Nat Genet. 2000;26(1):81-4.

28. Thomson JR, Machado RD, Pauciulo MW, Morgan NV, Humbert M, Elliott GC, et al. Sporadic primary pulmonary hypertension is associated with germline mutations of the gene encoding BMPR-II, a receptor member of the TGF-beta family. J Med Genet. 2000;37(10):741-5. 29. Trembath RC, Thomson JR, Machado RD, Morgan NV, Atkinson C, Winship I, et al. Clinical and molecular genetic features of pulmonary hypertension in patients with hereditary hemorrhagic telangiectasia. N Engl J Med. 2001;345(5):325-34.

30. Harrison RE, Berger R, Haworth SG, Tulloh R, Mache CJ, Morrell NW, et al. Transforming growth factor-beta receptor mutations and pulmonary arterial hypertension in childhood. Circulation. 2005;111(4):435-41.

31. Graf S, Haimel M, Bleda M, Hadinnapola C, Southgate L, Li W, et al. Identification of rare sequence variation underlying heritable pulmonary arterial hypertension. Nat Commun. 2018;9(1):1416.

32. Eyries M, Montani D, Nadaud S, Girerd B, Levy M, Bourdin A, et al. Widening the landscape of heritable pulmonary hypertension mutations in paediatric and adult cases. Eur Respir J. 2019;53(3).

33. Wang XJ, Lian TY, Jiang X, Liu SF, Li SQ, Jiang R, et al. Germline BMP9 mutation causes idiopathic pulmonary arterial hypertension. Eur Respir J. 2019;53(3). 
34. Wang G, Fan R, Ji R, Zou W, Penny DJ, Varghese NP, et al. Novel homozygous BMP9 nonsense mutation causes pulmonary arterial hypertension: a case report. BMC Pulm Med. 2016;16(1):17.

35. Nikolic I, Yung LM, Yang P, Malhotra R, Paskin-Flerlage SD, Dinter T, et al. Bone Morphogenetic Protein 9 Is a Mechanistic Biomarker of Portopulmonary Hypertension. Am J Respir Crit Care Med. 2019;199(7):891-902.

36. Tu L, Desroches-Castan A, Mallet C, Guyon L, Cumont A, Phan C, et al. Selective BMP-9 Inhibition Partially Protects Against Experimental Pulmonary Hypertension. Circ Res. 2019;124(6):846-55.

37. Torsney E, Charlton R, Diamond AG, Burn J, Soames JV, Arthur HM. Mouse model for hereditary hemorrhagic telangiectasia has a generalized vascular abnormality. Circulation. 2003;107(12):1653-7.

38. Weiss A, Attisano L. The TGFbeta superfamily signaling pathway. Wiley Interdiscip Rev Dev Biol. 2013;2(1):47-63.

39. Massague J. TGF-beta signal transduction. Annu Rev Biochem. 1998;67:753-91.

40. Shi Y, Massague J. Mechanisms of TGF-beta signaling from cell membrane to the nucleus. Cell. 2003;113(6):685-700.

41. Zhang YE. Non-Smad pathways in TGF-beta signaling. Cell Res. 2009;19(1):128-39.

42. Yadin D, Knaus P, Mueller TD. Structural insights into BMP receptors: Specificity, activation and inhibition. Cytokine Growth Factor Rev. 2016;27:13-34.

43. Gray AM, Mason AJ. Requirement for activin A and transforming growth factor--beta 1 pro-regions in homodimer assembly. Science. 1990;247(4948):1328-30.

44. Mi LZ, Brown CT, Gao Y, Tian Y, Le VQ, Walz T, et al. Structure of bone morphogenetic protein 9 procomplex. Proc Natl Acad Sci U S A. 2015;112(12):3710-5.

45. Sengle G, Ono RN, Sasaki T, Sakai LY. Prodomains of transforming growth factor beta (TGFbeta) superfamily members specify different functions: extracellular matrix interactions and growth factor bioavailability. J Biol Chem. 2011;286(7):5087-99.

46. Jiang H, Salmon RM, Upton PD, Wei Z, Lawera A, Davenport AP, et al. The Prodomainbound Form of Bone Morphogenetic Protein 10 Is Biologically Active on Endothelial Cells. J Biol Chem. 2016;291(6):2954-66.

47. Brown MA, Zhao Q, Baker KA, Naik C, Chen C, Pukac L, et al. Crystal structure of BMP-9 and functional interactions with pro-region and receptors. J Biol Chem. 2005;280(26):25111-8. 48. Wei Z, Salmon RM, Upton PD, Morrell NW, Li W. Regulation of Bone Morphogenetic Protein 9 (BMP9) by Redox-dependent Proteolysis. J Biol Chem. 2014;289(45):31150-9.

49. Appleby SL, Mitrofan CG, Crosby A, Hoenderdos K, Lodge K, Upton PD, et al. Bone Morphogenetic Protein 9 Enhances Lipopolysaccharide-Induced Leukocyte Recruitment to the Vascular Endothelium. J Immunol. 2016;197(8):3302-14.

50. Mitrofan CG, Appleby SL, Nash GB, Mallat Z, Chilvers ER, Upton PD, et al. Bone morphogenetic protein 9 (BMP9) and BMP10 enhance tumor necrosis factor-alpha-induced monocyte recruitment to the vascular endothelium mainly via activin receptor-like kinase 2 . J Biol Chem. 2017;292(33):13714-26.

51. Luo J, Tang M, Huang J, He BC, Gao JL, Chen L, et al. TGFbeta/BMP type I receptors ALK1 and ALK2 are essential for BMP9-induced osteogenic signaling in mesenchymal stem cells. J Biol Chem. 2010;285(38):29588-98.

52. Herrera B, van Dinther M, Ten Dijke P, Inman GJ. Autocrine bone morphogenetic protein-9 signals through activin receptor-like kinase-2/Smad1/Smad4 to promote ovarian cancer cell proliferation. Cancer Res. 2009;69(24):9254-62. 
53. Kienast Y, Jucknischke U, Scheiblich S, Thier M, de Wouters M, Haas A, et al. Rapid Activation of Bone Morphogenic Protein 9 by Receptor-mediated Displacement of Prodomains. J Biol Chem. 2016;291(7):3395-410.

54. Sengle G, Ono RN, Lyons KM, Bachinger HP, Sakai LY. A new model for growth factor activation: type II receptors compete with the prodomain for BMP-7. J Mol Biol. 2008;381(4):1025-39.

55. Upton PD, Davies RJ, Trembath RC, Morrell NW. Bone morphogenetic protein (BMP) and activin type II receptors balance BMP9 signals mediated by activin receptor-like kinase-1 in human pulmonary artery endothelial cells. J Biol Chem. 2009;284(23):15794-804.

56. Wu N, Zhao Y, Yin Y, Zhang Y, Luo J. Identification and analysis of type II TGF-beta receptors in BMP-9-induced osteogenic differentiation of C3H10T1/2 mesenchymal stem cells. Acta biochimica et biophysica Sinica. 2010;42(10):699-708.

57. Seemann P, Brehm A, Konig J, Reissner C, Stricker S, Kuss P, et al. Mutations in GDF5 reveal a key residue mediating BMP inhibition by NOGGIN. PLoS genetics. 2009;5(11):e1000747.

58. Yao Y, Jumabay M, Ly A, Radparvar M, Wang AH, Abdmaulen R, et al. Crossveinless 2 regulates bone morphogenetic protein 9 in human and mouse vascular endothelium. Blood. 2012;119(21):5037-47.

59. Aykul S, Martinez-Hackert E. Transforming Growth Factor-beta Family Ligands Can Function as Antagonists by Competing for Type II Receptor Binding. J Biol Chem. 2016;291(20):10792-804.

60. Yndestad A, Larsen KO, Oie E, Ueland T, Smith C, Halvorsen B, et al. Elevated levels of activin A in clinical and experimental pulmonary hypertension. J Appl Physiol (1985). 2009;106(4):1356-64.

61. Herrera B, Inman GJ. A rapid and sensitive bioassay for the simultaneous measurement of multiple bone morphogenetic proteins. Identification and quantification of BMP4, BMP6 and BMP9 in bovine and human serum. BMC Cell Biol. 2009;10:20.

62. Tillet E, Ouarne M, Desroches-Castan A, Mallet C, Subileau M, Didier R, et al. A heterodimer formed by bone morphogenetic protein 9 (BMP9) and BMP10 provides most BMP biological activity in plasma. J Biol Chem. 2018;293(28):10963-74.

63. Garcia de Vinuesa A, Abdelilah-Seyfried S, Knaus P, Zwijsen A, Bailly S. BMP signaling in vascular biology and dysfunction. Cytokine Growth Factor Rev. 2016;27:65-79.

64. Scheufler C, Sebald W, Hulsmeyer M. Crystal structure of human bone morphogenetic protein-2 at 2.7 A resolution. J Mol Biol. 1999;287(1):103-15.

65. Keller S, Nickel J, Zhang JL, Sebald W, Mueller TD. Molecular recognition of BMP-2 and BMP receptor IA. Nat Struct Mol Biol. 2004;11(5):481-8.

66. Allendorph GP, Isaacs MJ, Kawakami Y, Izpisua Belmonte JC, Choe S. BMP-3 and BMP-6 structures illuminate the nature of binding specificity with receptors. Biochemistry. 2007;46(43):12238-47.

67. Saremba S, Nickel J, Seher A, Kotzsch A, Sebald W, Mueller TD. Type I receptor binding of bone morphogenetic protein 6 is dependent on N-glycosylation of the ligand. FEBS J. 2008;275(1):172-83.

68. Griffith DL, Keck PC, Sampath TK, Rueger DC, Carlson WD. Three-dimensional structure of recombinant human osteogenic protein 1: structural paradigm for the transforming growth factor beta superfamily. Proc Natl Acad Sci U S A. 1996;93(2):878-83.

69. Greenwald J, Groppe J, Gray P, Wiater E, Kwiatkowski W, Vale W, et al. The BMP7/ActRII extracellular domain complex provides new insights into the cooperative nature of receptor assembly. Mol Cell. 2003;11(3):605-17. 
70. Padyana AK, Vaidialingam B, Hayes DB, Gupta P, Franti M, Farrow NA. Crystal structure of human GDF11. Acta Crystallogr F Struct Biol Commun. 2016;72(Pt 3):160-4.

71. Walker RG, Czepnik M, Goebel EJ, McCoy JC, Vujic A, Cho M, et al. Structural basis for potency differences between GDF8 and GDF11. BMC Biol. 2017;15(1):19.

72. Nickel J, Kotzsch A, Sebald W, Mueller TD. A single residue of GDF-5 defines binding specificity to BMP receptor IB. J Mol Biol. 2005;349(5):933-47.

73. Schreuder H, Liesum A, Pohl J, Kruse M, Koyama M. Crystal structure of recombinant human growth and differentiation factor 5: evidence for interaction of the type I and type II receptor-binding sites. Biochem Biophys Res Commun. 2005;329(3):1076-86.

74. Kirsch T, Sebald W, Dreyer MK. Crystal structure of the BMP-2-BRIA ectodomain complex. Nat Struct Biol. 2000;7(6):492-6.

75. Kotzsch A, Nickel J, Seher A, Heinecke K, van Geersdaele L, Herrmann T, et al. Structure analysis of bone morphogenetic protein-2 type I receptor complexes reveals a mechanism of receptor inactivation in juvenile polyposis syndrome. J Biol Chem. 2008;283(9):5876-87.

76. Allendorph GP, Vale WW, Choe S. Structure of the ternary signaling complex of a TGFbeta superfamily member. Proc Natl Acad Sci U S A. 2006;103(20):7643-8.

77. Weber D, Kotzsch A, Nickel J, Harth S, Seher A, Mueller U, et al. A silent H-bond can be mutationally activated for high-affinity interaction of BMP-2 and activin type IIB receptor. BMC Struct Biol. 2007;7:6.

78. Kotzsch A, Nickel J, Seher A, Sebald W, Muller TD. Crystal structure analysis reveals a spring-loaded latch as molecular mechanism for GDF-5-type I receptor specificity. EMBO J. 2009;28(7):937-47.

79. Klammert U, Mueller TD, Hellmann TV, Wuerzler KK, Kotzsch A, Schliermann A, et al. GDF-5 can act as a context-dependent BMP-2 antagonist. BMC Biol. 2015;13:77.

80. Healey EG, Bishop B, Elegheert J, Bell CH, Padilla-Parra S, Siebold C. Repulsive guidance molecule is a structural bridge between neogenin and bone morphogenetic protein. Nat Struct Mol Biol. 2015;22(6):458-65.

81. Zhang JL, Qiu LY, Kotzsch A, Weidauer S, Patterson L, Hammerschmidt M, et al. Crystal structure analysis reveals how the Chordin family member crossveinless 2 blocks BMP-2 receptor binding. Dev Cell. 2008;14(5):739-50.

82. Groppe J, Greenwald J, Wiater E, Rodriguez-Leon J, Economides AN, Kwiatkowski W, et al. Structural basis of BMP signalling inhibition by the cystine knot protein Noggin. Nature. 2002;420(6916):636-42.

83. Nolan K, Kattamuri C, Rankin SA, Read RJ, Zorn AM, Thompson TB. Structure of Gremlin2 in Complex with GDF5 Gives Insight into DAN-Family-Mediated BMP Antagonism. Cell Rep. 2016;16(8):2077-86. 
Table 1. Reported crystal structures of BMPs and their complexes, shown with Protein Data Bank (PDB) accession codes. In brackets are reference numbers where these structures were reported.

\begin{tabular}{|c|c|c|c|c|c|c|c|}
\hline & BMP2 & BMP3 & BMP6 & BMP7 & BMP9 & $\begin{array}{l}\text { BMP11 } \\
\text { (GDF11) }\end{array}$ & $\begin{array}{l}\text { BMP14 } \\
\text { (GDF5) }\end{array}$ \\
\hline Free ligand & $\begin{array}{l}3 \mathrm{BMP}(64) \\
1 \mathrm{REU}(65)\end{array}$ & 2QCQ(66) & $\begin{array}{l}2 Q C W(66) \\
2 R 52(67) \\
2 R 53(67)\end{array}$ & $\begin{array}{l}1 \mathrm{BMP}(68) \\
1 \mathrm{LXI}(69)\end{array}$ & $\begin{array}{l}1 Z K Z(47) \\
4 \mathrm{MPL}(48) \\
5105(24)\end{array}$ & $\begin{array}{l}5 \mathrm{E} 4 \mathrm{G}(70) \\
5 \mathrm{UHM}(71)\end{array}$ & $\begin{array}{l}1 \mathrm{WAQ}(72) \\
2 \mathrm{BHK}(73)\end{array}$ \\
\hline Ligand:receptor & $\begin{array}{l}1 \mathrm{ES7}(74) \\
1 \mathrm{REW}(65) \\
2 \mathrm{QJ} 9(75) \\
2 \mathrm{QJA}(75) \\
2 \mathrm{QJB}(75) \\
2 \mathrm{GOO}(76) \\
2 \mathrm{H} 64(77) \\
2 \mathrm{H} 62(77)\end{array}$ & & & 1LX5(69) & $4 \mathrm{FAO}(25)$ & & $\begin{array}{l}3 \mathrm{EVS}(78) \\
3 Q B 4(79)\end{array}$ \\
\hline $\begin{array}{l}\text { Ligand:co- } \\
\text { receptor }\end{array}$ & $\begin{array}{l}\text { 4UHY(80) } \\
4 U I 1(80) \\
4 U I 2(80) \\
4 U H Z(80) \\
4 U I 0(80)\end{array}$ & & & & $5 \mathrm{HZW}(24)$ & & \\
\hline $\begin{array}{l}\text { Ligand:ligand } \\
\text { trap }\end{array}$ & $3 B K 3(81)$ & & & $1 \mathrm{M} 4 \mathrm{U}(82)$ & & 5JHW(71) & $5 \mathrm{HK} 5(83)$ \\
\hline $\begin{array}{l}\text { Prodomain- } \\
\text { bound complex }\end{array}$ & & & & & $\begin{array}{l}4 Y C G(44) \\
4 Y C I(44)\end{array}$ & & \\
\hline
\end{tabular}


Table 2. Summary of current affinity measurements between BMP9 and its binding proteins

\begin{tabular}{|c|c|c|c|}
\hline $\begin{array}{c}\mathrm{K}_{\mathrm{d}} \text { or } \mathrm{EC}_{50} \\
(\mathrm{nM})^{*}\end{array}$ & BMP9 GFD & Pro-BMPg & Notes \\
\hline ALK1-Fc & $\begin{array}{l}0.023 \pm 0.0009 \\
<0.008 \\
0.031\end{array}$ & $\begin{array}{l}0.039 \pm 0.01 \\
<0.006\end{array}$ & $\begin{array}{l}20^{\circ} \mathrm{C} \text {, ELISA binding assay, } \mathrm{EC}_{50} \text {. Mi et al.(44) } \\
37^{\circ} \mathrm{C} \text {, Biacore. Kienast et al.(53) } \\
37^{\circ} \mathrm{C} \text {, Biacore. Townson et al.(25) }\end{array}$ \\
\hline ALK2-Fc & $70 \pm 40$ & $>100$ & $20^{\circ} \mathrm{C}$, ELISA binding assay, $\mathrm{EC}_{50}$. Mi et al.(44) \\
\hline BMPRII-FC & $\begin{array}{l}0.04 \pm 0.02 \\
3.3 \\
2.1 \\
7.44\end{array}$ & $\begin{array}{l}1.6 \pm 0.7 \\
3.2\end{array}$ & $\begin{array}{l}20^{\circ} \mathrm{C} \text {, ELISA binding assay, } \mathrm{EC}_{50} \text {. Mi et al.(44) } \\
37^{\circ} \mathrm{C} \text {, Biacore. Kienast et al.(53) } \\
37^{\circ} \mathrm{C} \text {, Biacore. Townson et al.(25) } \\
25^{\circ} \mathrm{C} \text {, Biacore. Aykul \& Martinez-Hackert(59) }\end{array}$ \\
\hline ActRIIb-Fc & $\begin{array}{l}0.04 \pm 0.02 \\
1.4 \\
0.033 \\
0.881\end{array}$ & $\begin{array}{l}0.2 \pm 0.1 \\
0.8\end{array}$ & $\begin{array}{l}20^{\circ} \mathrm{C} \text {, ELISA binding assay, } \mathrm{EC}_{50} \text {. Mi et al.(44) } \\
37^{\circ} \mathrm{C} \text {, Biacore. Kienast et al.(53) } \\
37^{\circ} \mathrm{C} \text {, Biacore. Townson et al.(25) } \\
25^{\circ} \mathrm{C} \text {, Biacore. Aykul \& Martinez-Hackert(59) }\end{array}$ \\
\hline ActRIla-Fc & $\begin{array}{l}0.5 \pm 0.2 \\
42.7 \\
10.37\end{array}$ & $\begin{array}{l}>100 \\
19.7\end{array}$ & $\begin{array}{l}20^{\circ} \mathrm{C} \text {, ELISA binding assay, } \mathrm{EC}_{50} . \mathrm{Mi} \text { et al.(44) } \\
37^{\circ} \mathrm{C} \text {, Biacore. Kienast et al.(53) } \\
37^{\circ} \mathrm{C} \text {, Biacore. Townson et al. }(25)\end{array}$ \\
\hline sENG-Fc & $\begin{array}{l}2.7 \\
0.032\end{array}$ & 1.5 & $\begin{array}{l}37^{\circ} \mathrm{C} \text {, Biacore. Kienast et al.(53) } \\
20^{\circ} \mathrm{C} \text {, Biacore. Castonguay et al. }(21)\end{array}$ \\
\hline sENG** & 9.81 & & ForeBio Octet Red96, Saito et al. (24) \\
\hline prodomain & $800-1000$ & & $15^{\circ} \mathrm{C}$, ITC. Mi et al.(44) \\
\hline
\end{tabular}

*Affinities are either expressed as $\mathrm{EC}_{50}$ measured by ELISA-based plate assays, or $\mathrm{K}_{\mathrm{d}}$ measured by Biacore, Octet or isothermal calorimetry (ITC).

**sENG: soluble endoglin 


\section{Figure legends:}

Figure 1 (A) Promiscuity in BMP family ligand-receptor recognition. The same BMP can signal through different receptor pairs, and similarly, the same receptor pair can mediate the signals from different BMPs. Data taken from summary in Yadin et al(42). Type II receptors could be BMPRII, ActRIIa or ActRIIb. (B) Extracellular protein-protein interaction network directly or indirectly involved in BMP9 signal transduction. BMP9 interacts with ALK1 or ALK2 through residues at the type I site. Type II site on BMP9 can form direct protein-protein interactions with multiple proteins, including BMP9 prodomain (BMP9pro), type II receptors (ActRIIa/b, BMPRII), cell surface and soluble ENG. CV2 has been shown to inhibit BMP9 activity, and crystal structure of CV2:BMP2 demonstrates that CV2 binds BMP at both type I and type II sites (81). BMPRII and ActRIIa/b also bind directly to other TGF $\beta$ family ligands, therefore ligand competition for the type II receptors could potentially regulate BMP9 activity(59). Cyan: ligands; Yellow: proteins that interact with the type I site on the ligands; Coral: proteins that interact with the type II site on the ligands. Lines indicate direct protein-protein interactions. (C) Crystal structures of BMP9 and its complexes. Each protein molecule is coloured in the same way as the label below. Type I and type II receptor binding sites are highlighted.

Figure 2. Activin A and BMP4 do not inhibit BMP9 signalling in hPAECs. (A) Serum-starved hPAECs were pre-treated with PBS or ActA (at 10x, 25x, 50x, 100x and 200x molar excess of BMP9) for 10 minutes to allow ActA pre-binding before treatment with PBS or BMP9 (at 0.3 ng/ml GFD concentration) for an additional 10 minutes, following which the cells were harvested for pSmad1/5 or pSmad2 immunoblotting. Since such a short time treatment will not cause change in total Smad levels, $\alpha$-tubulin probed on the same blot was used as loading controls. Band intensity of ActA effects on BMP9-induced Samd1/5 phosphorylation from three independent experiment were quantified using Image J and shown on the right. (B\&C) Serum- 
starved hPAECs were pre-treated with PBS or ActA (at 25x, 50x and 100x molar excess of BMP9) for 10 minutes and then treated with PBS or BMP9 (at $0.3 \mathrm{ng} / \mathrm{ml} \mathrm{GFD} \mathrm{concentration)} \mathrm{for} \mathrm{either}$ an additional 1 hour before qPCR analysis of ID2 (B) or an additional 5 hours before qPCR analysis for BMPR2 (C) mRNA expression, N=5. (D) Serum-starved hPAECs were pre-treated with PBS or BMP4 (at 10x, 25x, 50x, 100x and 200x molar excess of BMP9) for 10 minutes and then treated with PBS or BMP9 (at $0.3 \mathrm{ng} / \mathrm{ml}$ GFD concentration) for an additional 10 minutes, following which the cells were harvested for pSmad1/5 immunoblotting. Alpha-tubulin was used as loading control. One representative blot from three experiments is shown, with band intensity of BMP4 effects on BMP9-induced Smad1/5 phosphorylation quantified using Image J and shown on the right, N=3. (E\&F) Serum-starved hPAECs were pre-treated with PBS or BMP4 (at 25x, 50x and 100x molar excess of BMP9) for 10 minutes and then treated with PBS or BMP9 (at $0.3 \mathrm{ng} / \mathrm{ml}$ GFD concentration) for either an additional 1 hour before qPCR analysis of ID2 (E) mRNA expression or an additional 5 hours before qPCR analysis for BMPR2 (F) mRNA expression, $\mathrm{N}=5$. All graphs are shown as means \pm S.E.M. 
Figure 1

A

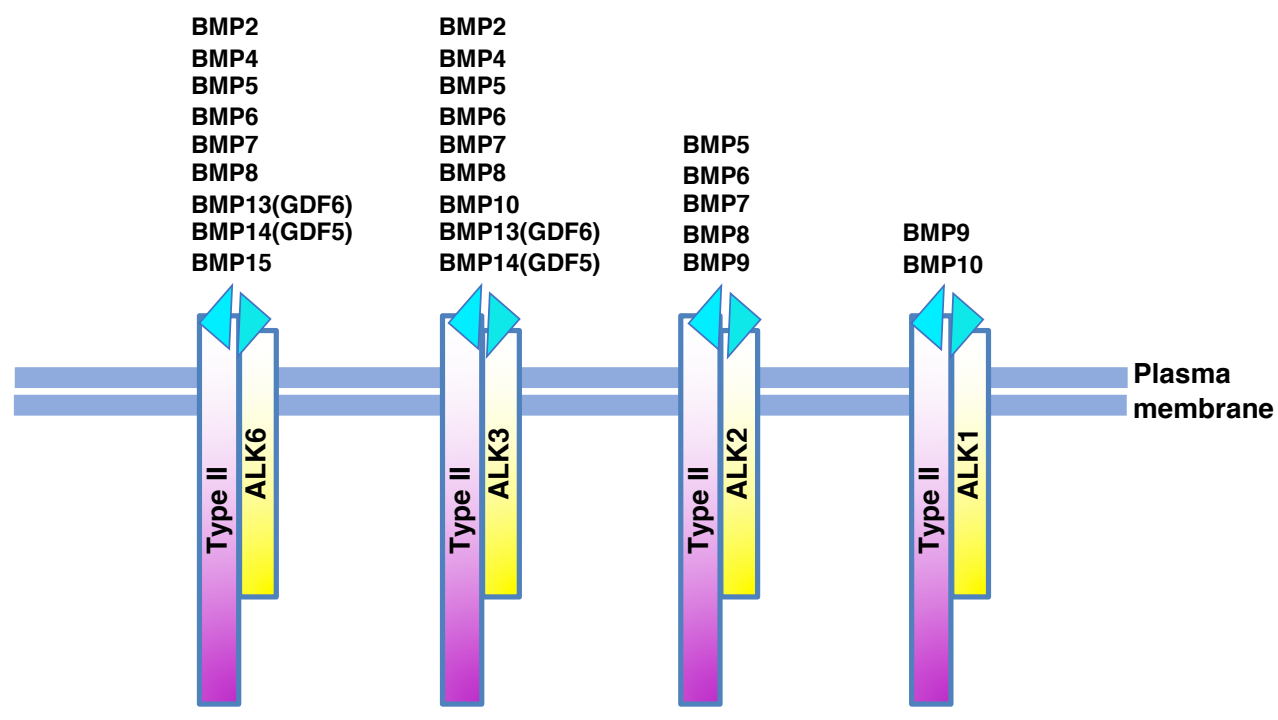

B

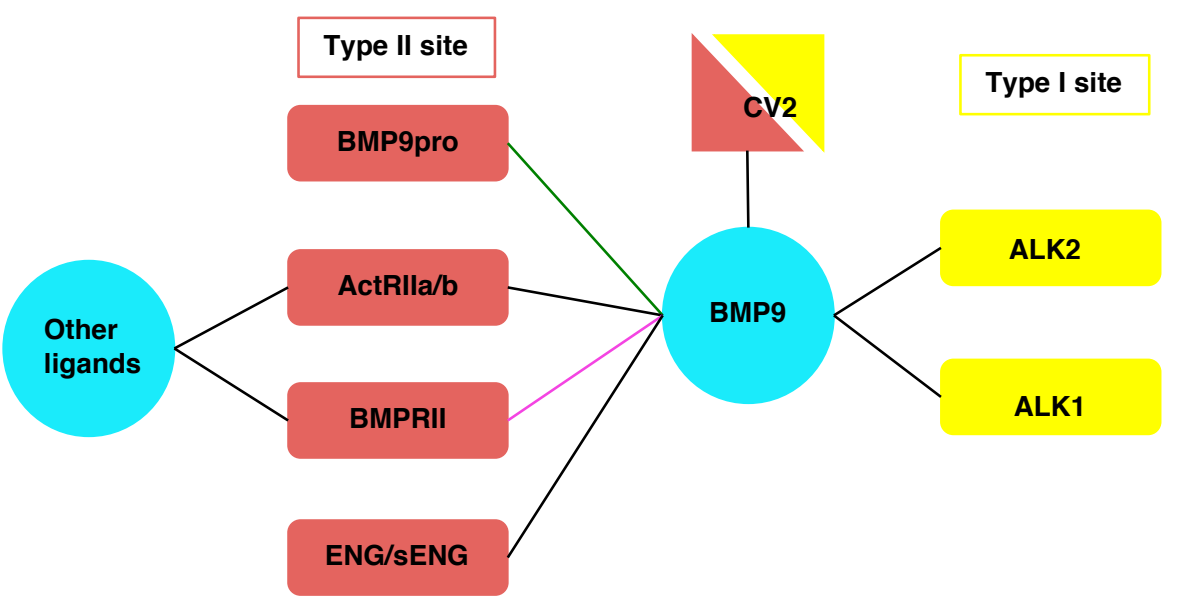

C

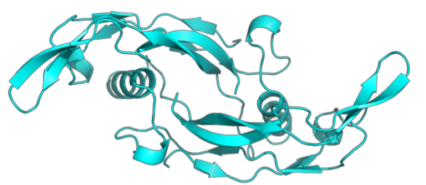

Type II site
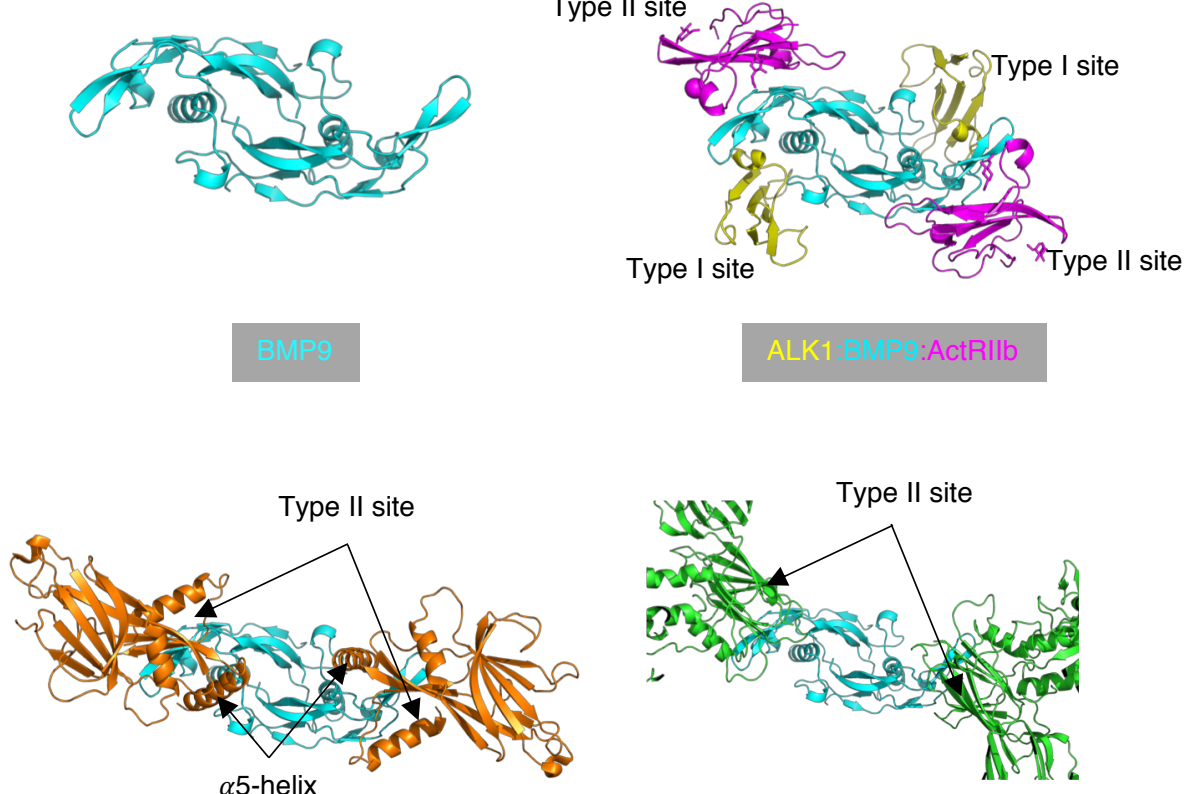

BIype:prodomain 


\section{Figure 2}
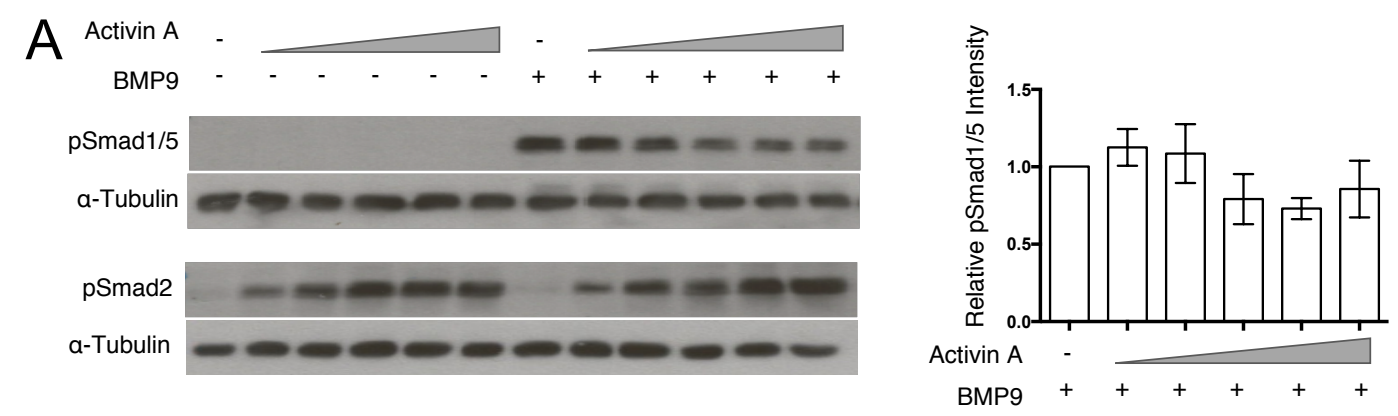

B
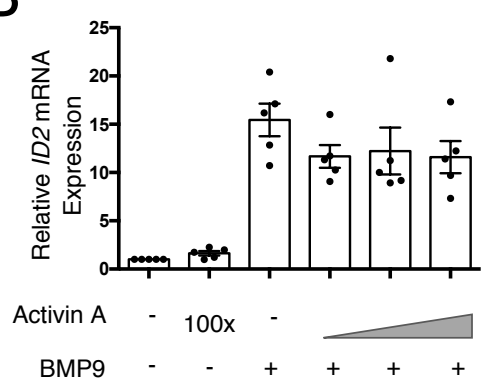

C

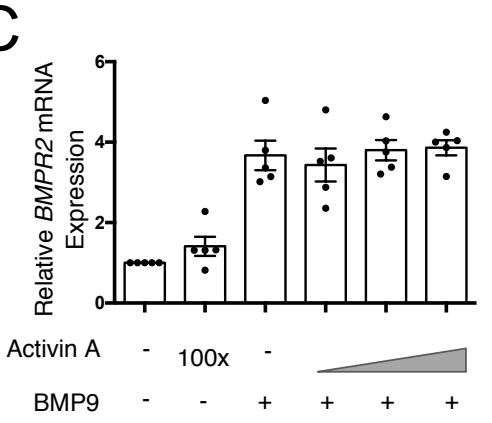

D
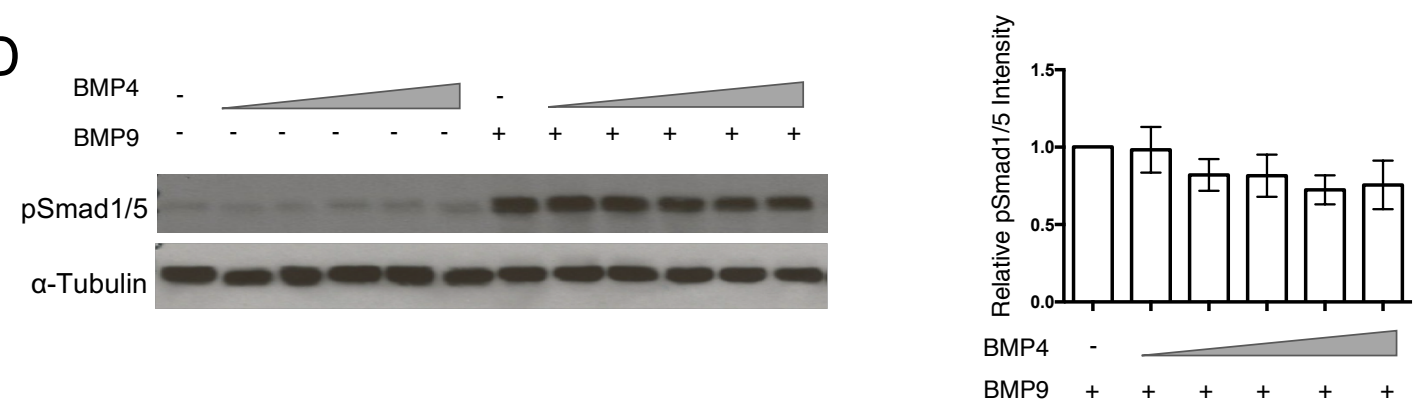

E

F
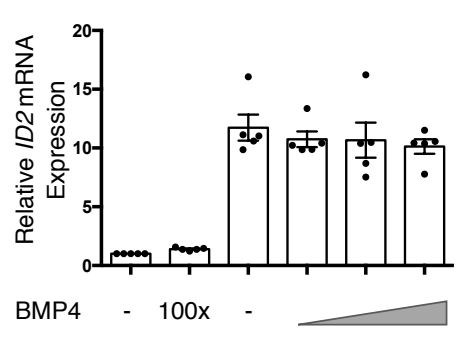

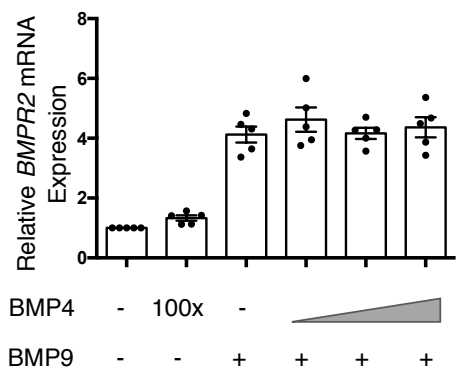

